\title{
Comparative analyses of thoracic radiographs and bronchoalveolar lavage of dogs and cats with chronic bronchial diseases
}

\author{
Análise comparativa da radiografia torácica e do lavado \\ broncoalveolar em cães e gatos com doença bronquial crônica
}

\author{
Mariana Pavelski ${ }^{*}$; Daniele Von Kruger Amaral2; Giovana Paladino Vieira²; \\ José Francisco Ghignatti Warth ${ }^{3}$; Rosangela Locatelli Dittrich ${ }^{3}$; \\ Peterson Triches Dornbusch ${ }^{3}$; Tilde Rodrigues Froes ${ }^{3}$
}

\begin{abstract}
There is a high incidence of bronchitis and asthma cases in veterinary medicine. Thoracic radiographs and bronchoalveolar lavage (BAL) are commonly performed for definitive diagnosis in dogs and cats with suspected bronchitis and asthma. It is believed that a combination of diagnostic tools is the best choice to achieve a diagnosis. The aim of this study was to evaluate the efficacy of thoracic radiographs and BAL in the diagnosis of chronic bronchial disease (CBD) in dogs and cats and whether there is any specific radiographic finding that could influence the indication for bronchoalveolar lavage. It was performed a cross-sectional, prospective, observational study including forty client-owned dogs and cats with lower respiratory tract signs and positive radiographic opacities that were evaluated with BAL followed by cytology and culture. The radiographic results compared with BAL culture showed a sensitivity of $38 \%$, specificity of $95 \%$ and accuracy of $65 \%$ in detecting patients with pneumonia associated with chronic bronchial disease. Thoracic radiographs were effective in diagnosing $65 \%$ of the patients, radiographs plus BAL cytology diagnosed $75 \%$ of patients and the combination of radiographs, BAL cytology and culture diagnosed $95 \%$ of the patients with chronic bronchial disease. In conclusion, the combination of radiographic examination with BAL followed by cytological and microbiological analyses increases diagnostic success in CBD.
\end{abstract}

Key words: Respiratory diseases. Diagnostic approach. Bronchoalveolar lavage.

\section{Resumo}

Existe uma alta incidência de casos de bronquite e asma em medicina veterinária. Radiografia torácica e lavado broncoalveolar (LBA) são geralmente realizados para o diagnóstico definitivo em cães e gatos com suspeita de bronquite e asma. Acredita-se que uma combinação de ferramentas diagnósticas é a melhor escolha para se obter um diagnóstico. O objetivo deste estudo foi avaliar a eficácia de radiografias torácicas e do LBA no diagnóstico da doença brônquica crônica (DBC) em cães e gatos e tentar determinar se há algum qualquer achado radiográfico específico que possa influenciar a indicação de lavado broncoalveolar. Foi realizado um estudo prospectivo, observacional, incluindo quarenta cães e gatos com sinais clínicos de trato respiratório inferior e aumento de opacidade radiográfica torácica, os quais foram avaliados com LBA seguido de citologia e cultura bacteriana. Os resultados radiográficos em

\footnotetext{
${ }^{1}$ Discente de Doutorado, Programa de Pós-Graduação em Ciências Veterinárias, Universidade Federal do Paraná, UFPR, Curitiba, PR, Brasil. E-mail: marimedvet@gmail.com

2 Médicas Veterinárias, Programa de Residência em Medicina Veterinária, UFPR, Curitiba, PR, Brasil. E-mail: dvonkruger@ gmail.com; gii.paladino@gmail.com

3 Profs. Adjuntos, Departamento de Medicina Veterinária, UFPR, Curitiba, PR, Brasil. E-mail: jfgwarth@gmail.com; roslocdi@ ufpr.br; petriches@gmail.com; tilde@ufpr.br

* Author for correspondence
} 
comparação com a cultura bacteriana do LBA mostraram uma sensibilidade de $38 \%$, especificidade de $95 \%$ e acurácia de $65 \%$ na detecção de pacientes com pneumonia associada à doença brônquica crônica. As radiografias torácicas foram eficazes em diagnosticar $65 \%$ dos pacientes, radiografia mais LBA seguido de citologia diagnosticaram $75 \%$ dos pacientes e a combinação de radiografias, LBA seguido de citologia e cultura bacteriana diagnosticaram 95\% dos pacientes com doença brônquica crónica. Em conclusão, a combinação de exame radiográfico torácico e LBA seguido de análise citológica e microbiológica aumenta o sucesso diagnóstico na DBC.

Palavras-chave: Doenças respiratórias. Abordagem diagnóstica. Lavado broncoalveolar.

\section{Introduction}

Accurate detection of any inflammatory disorder of the airways is essential for proper treatment, since disease progression can cause airway remodeling and predispose to complications (ZHU et al., 2015).

Chronic bronchitis in dogs, and asthma and bronchitis in cats are the main bronchial diseases in these species and have a high incidence in clinical practice. They are characterized by excessive mucus production and therefore result in chronic cough, difficult breathing and episodes of bronchospasm (BAY; JOHNSON, 2004; KUEHN, 2004; KIRSCHVINK et al., 2007; ETTINGER, 2013).

The presence of other concomitant diseases of respiratory origin, such as bronchopneumonia, neoplasia, eosinophilic bronchopneumopathy, bronchomalacia or even heart disorders such as mitral endocardiosis, may hinder the diagnosis of bronchial diseases because they have very similar clinical signs (PADRID, 2000; JOHNSON et al.., 2013; ROZANSKI, 2014; HAWKINS, 2014) It is believed that a combination of tests is the best method for diagnostic success (HAWKINS, 2014).

Radiographic examination is an essential diagnostic test for respiratory diseases. Despite sometimes giving an inconclusive result, a list of potential differential diagnoses can be made, and the need for additional tests can be based on the results of the thoracic radiographs (ROZANSKI, 2004; SAUNDERS; KEITH, 2004).

Among the imaging modalities, the greater availability of computed tomography in companion animal clinical practice is well known. Studies have demonstrated the likely increased sensitivity of computed tomography compared to radiography (PRATHER et al., 2005; SZABO et al., 2015). However, the limitation of tomography is similar to the radiographic examination, particularly when bacterial infection is suspected in patients with bronchial disease. This factor emphasizes the need for additional diagnostic modalities, such as bronchoalveolar lavage (BAL) followed by cytology and microbiological examination (SAUNDERS; KEITH, 2004; ETTINGER, 2013; THRALL, 2013).

The BAL is an inexpensive, minimally invasive examination, which allows cytological and microbiological examination of distal airways (ANDREASEN, 2003; ENGLISH et al., 2009). The BAL, with or without guidance by bronchoscopy, has been successfully employed in the diagnosis of respiratory disease in dogs and cats (HAWKINS et al., 1995; HAWKINS, 2004; NORRIS, 2002; YBARRA et al, 2012).

Studies show that the sensitivity and specificity of analog radiography for detecting dogs with chronic bronchitis vary from 56 to $65 \%$ and $91 \%$, respectively (MANTIS et al., 1998) In cats with inflammatory bronchial disease the sensitivity and specificity of radiographic examination varied from 71 to $89 \%$ and from 43 to $74 \%$, respectively. Another study found that the information obtained by BAL was able to support, or was even decisive for the establishment of, a final diagnosis in 75\% of dogs with respiratory disease (HAWKINS et al., 1995).

Thorax radiography and BAL have been studied in chronic bronchial diseases however these 
powerful diagnostic tools have not been studied together. (HAWKINS et al., 1995; YBARRA et al., 2012; JOHNSON et al., 2013; ROZANSKI, 2014; ZHU et al., 2015)

The aims of this study were to compare the effectiveness of radiographic examination and BAL analysis in the diagnosis of chronic bronchitis in dogs and bronchitis and asthma in cats, and also to determine whether there is a more specific radiographic finding that could influence the decision to performed BAL with cytological analysis, with or without microbiological evaluation, in these patients.

\section{Material and Methods}

\section{Study design and animal selection}

A prospective observational study was conducted in dogs and cats with clinical signs of lower respiratory disease. Dogs and cats of any breed, sex or age were recruited from May 2013 to February 2015. The inclusion criteria were clinical signs of cough, dyspnea or tachypnea lasting at least one month.

Every animal involved in the study underwent a physical examination, laboratory blood tests and thoracic radiography. As this study focused on non-neoplastic and non-cardiogenic diseases of the lower respiratory tract, animals with a suspected or confirmed diagnosis of cardiac disease, upper respiratory tract disease, neoplasm of the respiratory tract or lung metastases were excluded.

Selected dogs and cats in which pulmonary radiographic changes had been confirmed and did not present any of the exclusion criteria were kept in the study and subsequently underwent BAL.

This study was approved by the local Ethics Committee.

\section{Radiographic examination}

A computerized radiology technique was used for radiographic examination. The devices used were the Neo- Diagnomax. ZB-1 (Medicor Budapest ${ }^{\circledR}-$ Hungary) as the X-ray producer (500mA) and the CR 30-X AGFA (Agfa Healthcare ${ }^{\circledR}-$ Belgium) for digital processing. Images were acquired in DICOM format and interpreted in KPACS software (Imaging Information Systems Ltd. - United Kingdom).

Three views were taken for each animal: ventrodorsal and right and left lateral recumbencies. Radiographs were made carefully; following radiographic technique and positioning suggested by Rudorf et al. (2008). Expiratory radiographs were accepted in this study as some patients had respiratory restriction during the examination.

Final interpretation of radiographic examination was via the consensus of two radiologists in training, under the supervision of an experienced radiologist. Radiographic examinations were interpreted immediately after their acquisition, and the radiologists were not aware of the laboratory tests or BAL results.

The pulmonary radiographic appearance was carefully interpreted, searching for altered radiopacity. Increased opacity changes were classified according to the lung pattern nomenclature (SUTER, 1984) and the distribution of the lesions as focal or diffuse. The radiographs were also evaluated for the presence of bronchiectasis and hyperinflation.

In radiographs, dogs were considered positive for bronchitis when bronchial or bronchointerstitial patterns, either focal or diffuse and with or without an alveolar pattern, could be identified. In cats, bronchial or bronchointerstitial patterns, with or without an alveolar pattern, and signs of hyperinsufflation were related to bronchitis/asthma. The alveolar pattern, when present, was related to pneumonia associated with bronchial inflammatory disease. 


\section{Bronchoalveolar lavage technique}

Bronchoalveolar lavage was performed within three days from the time of thoracic radiography. The animals did not receive any medication during this period.

Prior to the BAL, the animals were fasted for 8 hours. Each animal was then sedated with meperidine $(5 \mathrm{mg} / \mathrm{kg} \mathrm{IM})$ followed by anesthesia with propofol $(4 \mathrm{mg} / \mathrm{kg}$ IV). With the patient positioned in lateral recumbency, 100\% oxygen was offered by endotracheal tube for a period of five minutes. Then, a sterile siliconized catheter for enteral feeding, adapted by removing the metallic end and adjusted to the size of the animal, was inserted into the tracheal tube, until resistance was encountered. A $0.9 \%$ saline solution (up to $4 \mathrm{ml} /$ $\mathrm{kg}$ in dogs and up to $3 \mathrm{ml} / \mathrm{kg}$ in cats) was infused, followed by $5 \mathrm{ml}$ of air to prevent the solution from remaining in the catheter. In animals over $10 \mathrm{~kg}$ of body weight, a standard total volume of $20 \mathrm{ml}$ of physiological solution was administered (RIBAS et al., 2010) The infused solution was immediately recovered in a syringe properly identified. This sample was properly stored in an ice-containing cooler which was sent for laboratory analysis immediately after collection. Blood pressure, heart rate and pulse oximetry, oxygen saturation were monitored throughout the procedure.

\section{Laboratory analysis of the bronchoalveolar lavage} fluid

Bronchoalveolar lavage fluid was processed immediately upon arrival at the laboratory. Macroscopic characteristics such as appearance and color, and microscopic characteristics such as quantity, quality and differential cell count (cellular differentiation) were analyzed. Five hundred microliters of the sample was separated for processing into Cytospin (ct14- Teklab ${ }^{\circledR}$ - Brazil) set at $1500 \mathrm{rpm}$ for $5 \mathrm{~min}$. The differential cell count was performed on Romanowsky stained preparations.
A total of 400 nucleated cells were counted in order to differentiate alveolar macrophages, foamy alveolar macrophages, lymphocytes, neutrophils, eosinophils and mast cells. The presence of mucus and epithelial cuboid columnar cells was evaluated via descriptive analysis and classified as grade 0 - absent, grade 1 - mild, grade 2 -moderate and grade 3 - pronounced. Neutrophils were considered degenerate when pyknosis, karyorrhexis or karyolysis were identified. The presence of Curschmann's spirals was also noted, which was associated with obstruction of the bronchioles and inflammatory disease (bronchitis/asthma).

Normal values previously established were used for the differential cytology results analysis of the lavage $^{16}$ (for dogs, 71\% alveolar macrophages, $17 \%$ lymphocytes, $5 \%$ neutrophils, $6 \%$ eosinophils and $2 \%$ mast cells; and for cats, $70 \%$ alveolar macrophages, 4\% lymphocytes, $6 \%$ neutrophils, $18 \%$ eosinophils and $1 \%$ mast cells). Neutrophilic and eosinophilic inflammation was associated with bronchial inflammatory disease in dogs and cats. Samples with cell counts below 300 were discarded, as were those in which oral contamination was documented (Simonsiella sp.).

The final results of the lung lavage cytology slide represented the consensus of two experienced clinical pathologists.

Another aliquot of the sample was sent to the microbiology laboratory for bacterial culture. Samples were considered positive when a significant bacterial growth included a single colony type, without contaminating pathogens. Interpretation of culture dishes and the susceptibility testing represented the consensus of two experienced microbiologists that looked at each sample.

In five cats we had the opportunity (owner's financial support) to send a BAL aliquot for polymerase chain reaction (PCR) analysis (Respiratory Panel of IDEXX®) which included: herpesvirus 1, Bordetella bronchiseptica, Chlamydophila felis, feline calicivirus, influenza virus and Mycoplasma felis. 


\section{Statistical analyses}

To compare the radiographic findings with the BAL culture results, sensitivity, specificity and accuracy were tested. An unpaired t-test was used for comparing BAL cytology cell differentials in different situations. Cytology of animals with an alveolar pattern and positive culture was compared to cytology of those with a positive culture and bronchial or bronchointerstitial pattern; for example, macrophages were compared to macrophages, neutrophils to neutrophils and so on, considering the whole cell differential of the BAL. Other t-tests were performed, without considering the culture results, to compare the cytology of animals with an alveolar pattern to the cytology of animals with a bronchial or bronchointerstitial pattern. All analyses were performed with the software Graphpad Prism (v.6, 2015).

\section{Results}

Forty animals were enrolled in the study, including 28 dogs of several breeds of either sex, with ages ranging between $5-14$ years (eight years on average), and 12 cats of several breeds of either sex, ranging in age from six months to six years (three years on average).

Reported clinical signs were coughing and dyspnea. For the dogs, 57.1\% $(\mathrm{n}=16)$ had a cough, $32.1 \%(\mathrm{n}=9)$ cough and dyspnea and $10.8 \%(\mathrm{n}=$ $3)$ only dyspnea. In cats, $67 \%(n=8)$ had dyspnea, $25 \%(\mathrm{n}=3)$ dyspnea and cough and $8 \%(\mathrm{n}=1)$ only cough. On average, the clinical signs had been progressive over the past 3.5 months in dogs and three months in cats.

Radiographic analysis of all dogs revealed a diffuse increase of pulmonary opacification, with a bronchial pattern in 10/28 and a bronchointerstitial pattern in 18/28. An alveolar pattern was seen in combination with a bronchial pattern in two dogs $(2 / 10)$, whereas five had a bronchointerstitial pattern (5/19) (Table 1).

Table 1. Radiographic findings in dogs and cats with inflammatory bronchial disease.

\begin{tabular}{ccccc}
\hline & \multicolumn{2}{c}{ DOGS (28) } & \multicolumn{2}{c}{ CATS (12) } \\
\hline Radiographic pattern & Diffuse & Focal & Diffuse (12) & Focal \\
Bronchial & $28.6 \%(8)$ & - & $25 \%(3)$ & - \\
Bronchointerstitial & $44.3 \%(13)$ & - & $58.3 \%(7)$ & - \\
Bronchointerstitial with focal alveolar pattern & $17.8 \%(5)^{\mathrm{a}}$ & $\mathrm{a}$ & $16.7 \%(2)^{\mathrm{c}}$ & $\mathrm{C}$ \\
Bronchial with focal alveolar pattern & $7.2 \%(2)^{\mathrm{b}}$ & $\mathrm{b}$ & - & - \\
\hline
\end{tabular}

${ }^{\mathrm{ab}}$ Alveolar pattern was classified as focal. The letters indicate repetition of the same animals, which have more than one pulmonary pattern.

In all cats $(n=12)$ the radiographic opacification was diffuse while a bronchial pattern was seen in $3 / 12$ and a bronchointerstitial pattern in 9/12. A focal alveolar pattern was observed in $2 / 12$ cats that had a bronchointerstitial pattern (Table 1). Bronchiectasis was seen in two cats and none of the dogs.

The cytological differential interpretations of the BAL from the dogs and cats are described in Table
2. Twenty-seven dogs and all cats had cytology findings compatible with inflammatory disease. The amount of mucus was classified as absent in 3.5\% $(\mathrm{n}=1)$ of dogs, mild in $32.14 \%(\mathrm{n}=9)$, moderate in $57 \%(n=16)$ and pronounced in $7.2 \%(n=2)$. In cats, the mucus was considered mild in $59 \%(\mathrm{n}=7)$, moderate in $16 \%(\mathrm{n}=2)$ and pronounced in $25 \%$ $(n=3)$. 
Table 2. Results of the differential cytological interpretation of the bronchoalveolar lavage of the dogs and cats.

\begin{tabular}{ccccc}
\hline BAL Cytology & Neutrophilic & Neutrophilic and & Eosinophilic & Macrophagic \\
$\%(\mathrm{n})$ & & Eosinophilic & & \\
Dogs $n=28$ & $64.2 \%(18)$ & $28.6 \%(8)$ & $3.57 \%(1)$ & $357 \%(1)$ \\
Cats $\mathrm{n}=12$ & $25 \%(3)$ & $50 \%(6)$ & $25 \%(1)$ & - \\
\hline
\end{tabular}

Curschmann's spirals were visualized in the BAL cytology in $38 \%(11 / 29)$ of the dogs which showed moderate to severe quantities of mucus. None of the cat BAL samples showed Curschmann's spirals.

Hypersegmented neutrophils were visualized in the BAL cytology in $4 / 12$ of cats and in $17 / 29$ of dogs. Degenerate neutrophils were identified in $6 / 12$ cats and $8 / 28$ dogs.

Of the cats with degenerate neutrophils, 33.33\% $(n=2)$ had a positive culture and $57.14 \%$ of the dogs with degenerate neutrophils also had a positive culture.
The BAL culture was positive in $64.2 \%(18 / 28)$ of the dogs and in $25 \%(3 / 12)$ of the cats. Of the 18 dogs with a positive culture, $33.3 \%(n=6)$ had radiographic opacification consistent with an alveolar pattern, which was considered supportive of pneumonia, while $66.7 \%(\mathrm{n}=12)$ had either a bronchial or bronchointerstitial radiographic pattern. Only one dog had an alveolar radiographic pattern together with bronchial disease and had a negative BAL culture (Table 3 ).

Table 3. Results of radiographic analysis and culture of bronchoalveolar lavage (BAL) in dogs ( $n=28)$.

\begin{tabular}{|c|c|c|}
\hline Radiographic pattern & Patients affected (n) & BAL culture results $(\mathrm{n} / \%)$ \\
\hline Diffuse bronchial & 8 & $\begin{array}{c}\text { Positive } 5 / 62.5 \% \\
\text { Negative } 3 / 37.5 \%\end{array}$ \\
\hline Diffuse bronchointerstitial & 13 & $\begin{array}{c}\text { Positive } 7 / 53.84 \% \\
\text { Negative } 6 / 46.15 \%\end{array}$ \\
\hline Diffuse bronchointerstitial with focal alveolar & 5 & $\begin{array}{c}\text { Positive } 4 / 80.0 \% \\
\text { Negative } 1 / 20.0 \%\end{array}$ \\
\hline Diffuse bronchial with focal alveolar & 2 & $\begin{array}{c}\text { Positive } 2 / 100 \% \\
\text { Negative } 0 / 0 \% \\
\end{array}$ \\
\hline
\end{tabular}

Among the three cats with a positive culture, $66.7 \% \quad(\mathrm{n}=2)$ had radiographic opacification consistent with an alveolar pattern and $33.3 \%(n=1)$ had a bronchointerstitial pattern (Table 4).

Phagocytized bacteria were viewed in the BAL cytology of two dogs, which also showed positive cultures, and of three cats, from which only one had a positive culture.
When comparing the thoracic radiograph results with the culture results, the radiographic examination was determined to have $38 \%$ sensitivity, $95 \%$ specificity and $65 \%$ accuracy in detecting patients with pneumonia secondary to bronchial inflammatory disease. 
Table 4. Results of radiographic analysis and culture of bronchoalveolar lavage (BAL) in cats ( $n=12)$.

\begin{tabular}{lcc}
\hline \multicolumn{1}{c}{ Radiographic pattern } & Patients affected (n) & BAL culture results (n / \%) \\
\hline Diffuse bronchial & 3 & Positive $0 / 0 \%$ \\
Negative $3 / 100 \%$ \\
Diffuse bronchointerstitial & 7 & $\begin{array}{c}\text { Positive } 1 / 14.28 \% \\
\text { Negative } 6 / 85.71 \% \\
\text { Diffuse bronchointerstitial with focal alveolar }\end{array}$ \\
Diffuse bronchial with focal alveolar & 2 & Positive $2 / 100 \%$ \\
\hline
\end{tabular}

The differential cytology (macrophages, neutrophils, lymphocytes, eosinophils) of animals with an alveolar pattern and positive culture, compared to the cytology of those with other lung patterns not indicative of pneumonia along with positive culture, was not statistically different ( $p$ $<0.05)$. Likewise, the BAL cellular differential, regardless of the outcome of the culture, was not statistically different between the different lung patterns $(\mathrm{p}<0.05)$.
Among the 40 evaluated animals, all presented altered cytology and of these, only twenty-one had positive cultures. When relating the BAL cell differential of the animals with positive cultures to the ones with negative cultures, regardless of radiographic pattern, no statistical difference was shown $(p<0.05)$. Neutrophils in the BAL were identified in cases of both positive and negative cultures (Table 5).

Table 5. Number and percentage of animals with positive culture related to the cytology of the bronchoalveolar lavage (BAL).

\begin{tabular}{lcccc}
\hline \multicolumn{1}{c}{ BAL cytology } & Dogs & $\begin{array}{c}\text { Positive culture } \\
\text { Dogs }\end{array}$ & Cats & $\begin{array}{c}\text { Positive culture } \\
\text { Cats }\end{array}$ \\
\hline Neutrophilic & 18 & $13(72.22 \%)$ & 3 & $1(33.33 \%)$ \\
Neutrophilic and eosinophilic & 8 & $5(62.5 \%)$ & 6 & $1(33.33 \%)$ \\
Eosinophilic & 1 & - & 3 & $1(33.33 \%)$ \\
Macrophagic & 1 & $1(100 \%)$ & - & - \\
\hline
\end{tabular}

In five cats in which PCR was performed from the BAL samples, one was positive for calicivirus, another for Bordetella bronchiseptica, calicivirus and Mycoplasma and the third only for Bordetella. Two cats were absolutely negative.

Out of the 40 animals evaluated, in $42.5 \%$ (n $=17$ ) similar results were seen between the three examinations (radiography, BAL cytology and BAL culture). For the remaining animals there were similar results between at least two of the tests (Table 6).

Combining the clinical signs with the results of thoracic radiography and BAL cytology a final diagnosis of bronchial inflammatory disease associated with pneumonia was obtained in 18/28 dogs and bronchial inflammatory disease in 10/28 dogs. In cats, 3/12 were diagnosed with bronchial inflammatory disease associated with pneumonia and $9 / 12$ with bronchial inflammatory disease (Table 5).

The thoracic radiograph as a single technique was effective in determining the diagnosis in $65 \%$ $(\mathrm{n}=26)$ of patients. When combined with $\mathrm{BAL}$ cytology, it was effective in $75 \%(n=30)$ of patients, and finally, when combining radiography, cytology and lavage culture, it was possible to determine 
the final diagnosis in $95 \%(\mathrm{n}=38)$ of patients. Although radiography was supportive of bronchial disease, two cats had negative cultures but were PCR positive for Bordetella bronchispetica, which indicated infection.

Table 6. Number and percentage of animals (28 dogs and 12 cats) affected comparing the three tests performed and the final diagnosis.

\begin{tabular}{lccl}
\hline & Dogs (28) & Cats (12) & \multicolumn{1}{c}{ Diagnosis } \\
\hline $\begin{array}{l}\text { Radiography BA/BIA* } \\
\text { Altered cytology * }\end{array}$ & $21.5 \%(6)$ & $16,7 \%(2)$ & $\begin{array}{l}\text { Inflammatory bronchial disease and } \\
\text { pneumonia }\end{array}$ \\
$\begin{array}{l}\text { Positive culture } \\
\text { Radiography BIA * } \\
\text { Altered cytology * }\end{array}$ & $3,57 \%(1)$ & - & Inflammatory bronchial disease \\
$\begin{array}{l}\text { Negative culture } \\
\text { Radiography B/BI* } \\
\text { Altered cytology * }\end{array}$ & $42,8 \%(12)$ & $8,3 \%(1)$ & $\begin{array}{l}\text { Inflammatory bronchial disease and } \\
\text { pneumonia }\end{array}$ \\
$\begin{array}{l}\text { Positive culture } \\
\text { Radiography B/IB* } \\
\text { Altered cytology * } \\
\text { Negative culture }\end{array}$ & $32.2 \%(9)$ & $75 \%(9)$ & Inflammatory bronchial disease \\
\hline
\end{tabular}

* BA- diffuse bronchial with focal alveolar pattern, BIA- diffuse interstitial and bronchial with focal alveolar pattern, B- diffuse bronchial, BI - diffuse interstitial and bronchial.

\section{Discussion}

The high incidence of chronic bronchitis in dogs and asthma and bronchitis in cats, makes essential to determine the best way to manage such patients in order to avoid incorrect diagnoses. This study confirmed that the best way of establishing a diagnosis is by a combination of thoracic radiographic examination and BAL followed by cytological and microbiological analysis (HAWKINS, 2014).

The clinical signs and time frame presented by the dogs and cats recruited for this study reflect what is described in the literature on dogs and cats with $\mathrm{CBD}$, with the main signs being cough and dyspnea with more than two months duration (FOSTER et al., 2004a; ROZANSKI, 2004; ETTINGER, 2013; HAWKINS, 2014; ROZANSKI, 2014). As for the starting age of the disease in dogs, the mean of eight years was similar to that described (WHEELDON et al., 1979; ROZANSKI, 2014). In cats there are discrepancies in the literature regarding the age of occurrence of chronic bronchitis and asthma.
While some authors comment that the disease is most common between eight and ten years of age, others report the appearance of signs between four and five years of age, or even that bronchial disease can occur in cats of any age (YBARRA et al., 2012; HAWKINS, 2014; TRZIL; REINEIRO, 2014). The average age obtained in this study was of three years, yet the population size may not have been large enough for this to be relevant.

Most dogs and cats in this study presented bronchial or bronchointerstitial radiographic patterns on the thoracic radiography (Table 1), which were displayed due to bronchial and peribronchial inflammatory infiltrates promoted by CBD (HAWKINS, 2014; THRALL, 2013). For some researchers, radiographic identification of bronchitis corresponds to swelling of the bronchial mucosa, mucosal hyperplasia, accumulation of mucus and inflammation of the peribronchial tissue (WHEELDON et al., 1979; SUTER, 1984; MANTIS et al., 1998). 
In this study the higher accuracy of radiographic examination in the detection of chronic bronchitis in dogs and cats was probably due to the improved image quality provided by the computerized radiographic technique, since only one dog that presented radiographic opacification did not have conclusive chronic bronchitis via BAL. However improvement in the quality of radiographic examination helps to identify more artifacts or incidental findings, like lung changes due to aging, especially in dogs, which eventually could hinder the interpretation (SUTER, 1984; MANTIS et al., 1998).

Two animals showed bronchiectasis, which is bronchial dilation attributable to remodeling of the bronchial wall, related to the progression of CBD (HAWKINS et al., 2003). Some other animals might have already had bronchiectasis at the time of the study, even though it was not seen on thoracic radiographs because of the low sensitivity of this test for this purpose, as the recommended diagnostic technique is computed tomography (MYER; BURT, 1973; HAWKINS et al., 2003).

In addition to bronchial or bronchointerstitial patterns, it is noteworthy that $25 \%$ of dogs and $16.7 \%$ of cats presented concomitant alveolar patterns on radiographic examination, which is associated with pneumonia (THRALL, 2013). Bacterial infection is one of the complications of CBD, especially in dogs, and therefore it should be investigated so that appropriate therapy is given to the patient (McKIERNAN, 2000; ROZANSKI, 2014). On the other hand, alveolar patterns in cats, specifically in cases of chronic bronchitis and asthma, may be due to pulmonary atelectasis caused by bronchial obstruction of inflammatory cells, since excessive mucus or endobronchial exudate might cause obstruction of this airway segment. This fact undoubtedly complicates the correlation between alveolar patterns and contamination (pneumonia in cats); it is also known that this obliteration occurs mainly in the right middle lobe, although it is not common (CORCORAN et al., 1995). We should be cautious, therefore, when interpreting the association between bronchial and alveolar opacification in cats, mainly because there was bacterial growth in the two cats with focal alveolar patterns (Table 4). This discussion highlights once again the need for a combination of diagnostic techniques regardless of the species.

It is remarkable that of the animals in which the radiographs were not suggestive of pneumonia (bronchointerstitial and bronchial pattern only), $57.2 \%$ of dogs and $33.3 \%$ of cats had positive cultures (Table 3 and 4); therefore, while it is less common, the bronchial pattern can also be related to pneumonia (THRALL, 2013). Even the interstitial pattern can evolve into an alveolar pattern, but this will only become radiographically visible when a larger area is affected, such as if the alveoli are affected, if cell infiltration is concentrated around the bronchi denoting the formation of air bronchograms or also if it expands into the periphery of the lobes forming a lobar sign (THRALL, 2013). On the other hand, the patients with an alveolar pattern, which indicates pneumonia, were truly positive on culture.

Based on these results, a specificity of $95 \%$ and sensitivity of $38 \%$ was documented for radiography in detecting pneumonia in patients with CBD. Given this, we can suggest that when an alveolar pattern is identified, the patient likely has a bacterial infection, in which case the BAL followed by culture can be performed to provide appropriate therapy for the patient. However, when an alveolar pattern is not identified, bacterial contamination cannot be ruled out because the sensitivity of radiography is low for documenting contamination. Therefore, in these cases it is appropriate to perform a BAL in order to exclude bacterial contamination through culture and other cytological findings. The BAL is necessary because of the diagnostic gap of thoracic radiography, which is solely an ancillary technique as suggested by other authors of patients with CBD (ENGLISH et al., 2009; ROZANSKI, 2014; HAWKINS, 2014; ZHU et al., 2015). 
Bronchoalveolar lavage cytology of patients in this study presented an inflammatory nature, often represented by infiltration of neutrophils, neutrophils associated with eosinophils or also sole eosinophil infiltration. These represent the cytological findings described for dogs and cats with CBD (McKIERNAN, 2000; KUEHN, 2004; ROZANSKI, 2014; HAWKINS, 2014). The eosinophilic inflammation alone or combined with neutrophilic inflammation may be the main finding as seen in the cytology of $50 \%$ of the cats in this study (BAY; JOHNSON, 2004; YBARRA et al., 2012). Isolated eosinophilic BAL in dogs was seen in one patient of this study, which in addition to $\mathrm{CBD}$, can be associated with eosinophilic bronchopneumopathy, hypersensitivity or the presence of parasites (PRATHER et al., 2005; ROZANSKI, 2014).

The neutrophils present in the BAL could not be associated with any other test in this study. Neutrophilic BAL was observed in cytology regardless of radiographic pattern, whether indicative of pneumonia or inflammatory disease only. Neutrophilic inflammation was also present regardless if the culture was positive or negative. The neutrophilic BAL and the presence of hypersegmented neutrophils on cytology is sometimes wrongly associated with infectious processes, when in fact it is simply the reflection of airway inflammation due to CBD (McKIERNAN, 2000).

Another factor is the presence of degenerate neutrophils on BAL cytology, which may be a sign of bacterial infection (HAWKINS, 2004). Indeed, $46 \%(6 / 13)$ of patients with degenerate neutrophils had a positive culture. Unfortunately, in this study it was not possible to confirm this relationship as 54\% (7/13) of the animals with degenerate neutrophils had negative cultures. Also, 76\% (16/21) of all animals with positive cultures did not show degenerate neutrophils on cytology.

In this study, two cats in which phagocytosed bacteria were observed in BAL samples had negative cultures, which contrasts with literature that describes that the documentation of phagocytosed bacteria on BAL cytology suggests an infectious process (HAWKINS, 2004). Despite the negative culture, when PCR of the BAL was performed, there was positivity for Bordetella bronchiseptica in both cats, and one of them was simultaneously positive for Mycoplasma. Given this result it can be said that when phagocytosed bacteria are seen on cytology, the patient most likely has a CBD condition with an infectious agent(s) associated, but the opposite is not completely true.

In the case of the two cats reported before, it was only possible to identify the infectious agents involved by PCR of the BAL samples. In fact, culture can present false negatives when identifying bacteria, especially in the case of Mycoplasma (SUTER, 1984; REED et al., 2012; FOSTER et al., 2004a). Real time PCR is not part of the daily clinical routine, but future studies can be performed in dogs and cats with CBD combining this method as a diagnostic tool.

Bacteria were also visualized on cytology from two dogs in this study and culture was positive for both. On the other hand, if bacteria are not displayed on cytology it is not possible to state that infectious agents are not present considering that of 21 animals with positive cultures, only $14.3 \%$ had phagocytosed bacteria visualized on BAL cytology (HAWKINS, 2014).

Mucus was observed on cytology in most dogs and cats of this study and ranged from mild to severe. This is a very characteristic feature of animals with CBD which is related to chronic airway inflammation (WHELDOON et al., 1979; BAY; JOHNSON, 2004; ENGLISH et al., 2009).

Curschmann's spirals were displayed in $38 \%$ of dogs in this study, which may indicate bronchiole obstruction, and are believed to be a result of the intense production of mucus due to CBD (ADREASSEN, 2003; ENGLISH et al., 2009). None of the cats showed Curschmann's spirals, 
which is similar to other studies (McCARTHY; QUINN, 1989; LÉCUYER et al., 1995; FOSTER et al., 2004b).

Several cytological findings can be obtained from the BAL. However these results need to be analyzed together with patient clinical signs and radiography results for greater understanding of the result obtained (ENGLISH et al., 2009).

While the non-bronchoscopic lavage is indicated in diffuse conditions, we consider not using bronchoscopy to be a limitation of this study (HAWKINS, 2014). More data is likely to be obtained with bronchoscopy as it allows direct visualization of the airways. Also the lavage might have been performed on the least affected lung lobe. Moreover, multiple collection BAL foci already have been used YBARRA et al., 2012). Not performing heartworm testing was another limitation, although the patients lived in a nonendemic area for heartworm disease. Lastly, not investigating for lung parasites in order to exclude differential diagnoses was another limitation.

When comparing the results of the tests performed in this study, we found that with the combination of thoracic radiography and BAL cytology and culture, it was possible to obtain up to $95 \%$ of correct diagnoses in dogs and cats with CBD. Therefore, we believe BAL increases the diagnostic accuracy for dogs and cats with CBD.

\section{Conclusions}

Thoracic radiography is efficient in detecting CBD in dogs and cats and BAL cytology can help to confirm the suspicion. Since many animals with CBD develop associated infectious conditions, when a bronchointerstitial or alveolar patterns are documented on thoracic radiographs, BAL is indicated to rule out and/or identify the possible infectious. The combination of radiographic examination with BAL followed by cytological and microbiological analyses increases diagnostic success in CBD.

\section{Acknowledgement}

This study was supported by the National Counsel of Technological and Scientific Development CNPq (Proc. 471733/2013-0) and we would like to thank the Coordination for the Improvemet of Higher Education Personnel - Capes for the scholarship.

\section{References}

ANDREASEN, C. B. Bronchoalveolar lavage. Veterinary Clinics of North American Small Animal Practice, v. 33, n. 1, p. 69-88, 2003.

BAY, J. D.; JOHNSON, L. R. Feline bronchial disease/ Asthma. In: KING, L. G. Textbook of respiratory disease in dogs and cats. St. Louis: Saunders, 2004. p. 388-398.

CORCORAN, B. M.; FOSTER, D. J.; FUENTES, V. L. Feline asthma syndrome: a retrospective study of the clinical presentation in 29 cats. Journal of Small Animal Practice, Oxford, v. 36, n. x, p. 481-488, 1995.

ENGLISH, K.; COWELL, R. L.; TYLER, R. D.; MEINKOTH, J. H. Tracheal wash and bronchoalveolar lavage. In: COWELL, R. L.; TYLER, R. D.; MEINKOTH, J. H.; DENICOLA, D. B. Diagnostic cytology and hematology in dogs and cats. St. Louis: Mosby, 2009. p. 256-276.

ETTINGER, S. J. Disease of the trachea and upper airways. In: ETTINGER, S. J.; FELDMAN, E. C. Textbook of veterinary internal medicine. St. Louis: Sauders, 2013. p. 25-60.

FOSTER, S. F.; ALLAN, G. S.; MARTIN, P.; ROBERTSON, I. D.; MALIK, R. Twenty-five cases of feline bronchial disease (1995-2000). Journal of Feline Medicine and Surgery, v. 6, n. 3, p. 181-188, 2004a.

FOSTER, S. F.; MARTIN, P.; BRADDOCK, J. A.; MALIK, R. A retrospective analysis of feline bronchoalveolar lavage cytology and microbiology (1995-2000). Journal of Feline Medicine and Surgery, v. 6, n. 3, p. 189-198, 2004b.

HAWKINS, E. C.; BASSECHES, J.; BERRY, C. R.; STEBBINS, M. E.; FERRIS, K. K. Demographic, clinical and radiographic features of bronchiectasis in dogs: 316 cases. Journal of American Veterinary Medical Association, v. 223, n. 11, p. 1628-1635, 2003.

HAWKINS, E. C.; DENICOLA, D. B.; PLIER, M. L. Cytological analysis of bronchoalveolar lavage fluid in the diagnosis of spontaneous respiratory tract disease in 
dogs: a retrospective study. Journal of Veterinary Internal Medicine, Lakewood, v. 9, n. 6, p. 386-392, 1995.

HAWKINS, E. C. Bronchoalveolar lavage. In: KING, L. G. Respiratory diseases in dogs and cats. St. Louis: Saunders; 2004. p. 118-128.

Respiratory system disorders. In: NELSON, R. W.; COUTO, C. G. Small animal internal medicine. St. Louis: Saunders, 2014. p. 217-366.

JOHNSON, L. R.; QUEEN, E. V.; VERNAU, W.; SYKES, J. E.; BYRNE, B. A. Microbiologic and cytologic assessment of bronchoalveolar lavage fluid from dogs with lower respiratory tract infection: 105 cases (2001-2011). Journal of Veterinary Internal Medicine, Lakewood, v. 27, n. 2, p. 259-267, 2013.

KIRSCHVINK, N.; KERSNAK, E.; LEEMANS, J.; DELVAUX, F.; CLERCX, C.; SNAPS, F. Effects of age and allergen-induced airway inflammation in cats: radiographic and cytologic correlation. The Veterinary Journal, v. 174, n. 3, p. 644-651, 2007.

KUEHN, N. F. Chronic bronchitis in dogs/Asthma. In: KING, L. G. Textbook of respiratory disease in dogs and cats. St. Louis: Saunders, 2004. p. 379-387.

LÉCUYER, M.; DUBÉ, P. G.; DIFRUSCIA， R.; DESNOYERS, M.; LAGACÉ, A. Bronchoalveolar lavage in normal cats. Canadian Veterinary Journal, Guelph, v. 36, n. 11, p. 771-773, 1995.

MANTIS, P.; LAMB, C. R.; BOSWOOD, A. Assessment of the accuracy of thoracic radiography in the diagnosis of canine chronic bronchitis. Journal of Small Animal Practice, Oxford, v. 39, n. 11, p. 518-520, 1998.

McCARTHY, G. M.; QUINN, P. J. Bronchoalveolar lavage in the cat: cytological findings. Canadian Journal of Veterinary Research, Ottawa, v. 53, n. 2, p. 259-263, 1989.

McKIERNAN, B. C. Diagnosis and treatment of canine chronic bronchitis. Twenty years of experience. Veterinary Clinics North American Small Animal Practice, v. 30, n. 6, p. 1267-1278, 2000.

MYER, W.; BURT, J. Bronchiectasis in the dog; its radiographic appereance. Journal of American Veterinary Radiology, v. 14, p. 3-12, 1973.

NORRIS, C. R. Thoracic radiography, bronchoaveolar lavage cytopathology, and pulmonary parenchymal histopathology: a comparison of diagnostic results in 11 cats. Journal of American Animal Hospital Association, v. 38 , n. 4, p. 337-346, 2002.

PADRID, P. Feline asthma. Veterinary Clinics North American Small Animal Practice, v. 30, n. 8, p. 12791293, 2000.
PRATHER, A. B.; BERRY, C. R.; THRALL, D. E. Use of radiography in combination with computed tomography for the assessment of noncardiac thoracic disease in the dog and cat. Veterinary Radiology and Ultrasound, v. 46, n. 2, p. 114-121, 2005.

REED, N.; SIMPSON, K.; AYLING, R.; NICHOLAS, R.; GUNN-MOORE, D. Mycoplasma species in cats with lower airway disease: improved detection and species identification using a polymerase chain reaction assay. Journal of Feline Medicine and Surgery, v. 14, n. 12, p. 833-840, 2012.

RIBAS, C. R.; DORNBUSCH, P. T.; CIRIO, S. M.; ROCHA, R. M. V. M.; CAPRIGLIONE, L. G. A.; FAM, A. L. P. D. Citologia de lavado broncoalveolar de cães: Comparação entre lâminas a fresco e conservadas em formol. Archives of Veterinary Science, Curitiba, v. 15, $\mathrm{n}$. 2, p. 69-76, 2010.

ROZANSKI, E. A.; RUSH, J. E. Acute and chronic cough. In: KING, L. G. Textbook of respiratory disease in dogs and cats. St. Louis: Saunders, 2004. p. 42-46.

ROZANSKI, E. Canine chronic bronchitis. Veterinary Clinics North American Small Animal Practice, v. 44, n. 1, p. 107-116, 2014.

RUDORF, H.; TAEYMANS, H.; JOHNSON, V. Basics of thoracic radiography and radiology. In: SCHAWARZ, T.; JOHNSON, V. BSVA manual of canine and feline thoracic imaging. [S.1.]: British Small Animal Association, 2008. p. 1-19.

SAUNDERS, H. M.; KEITH, D. Thoracic imaging asthma. In: KING, L. G. Textbook of respiratory disease in dogs and cats. St. Louis: Saunders, 2004. p. 72-93.

SUTER, P. F. Normal radiographic anatomy and radiographic examination; Special procedures for the diagnosis of thoracic disease; Methods of radiographic interpretation, radiographic signs and dynamic factors in the radiographic diagnosis of thoracic diseases. In: Thoracic radiography: a text atlas of thoracic diseases of the dog and cat. Switzerland: Weltswil, 1984. p. 1-46, 47-76, 77-126.

SZABO, D.; SUTHERLAND-SMITH, J.; BARTON, B.; ROZANSKI, E. A.; TAEYMANS, O. Accuracy of a computed tomography bronchial wall thickness to pulmonary artery diameter ratio for assessing bronchial wall thickening in dogs. Veterinary Radiology and Ultrasound, Malden, v. 56, n. 3, p. 264-271, 2015.

THRALL, D. E. Disorders of thrachea and bronchi. In: . Textbook of veterinary diagnostic radiology. St. Louis: Saunders, 2013. p. 608-631. 
TRZIL, J. E.; REINERO, C. R. Update on feline asthma. Veterinary Clinics of North American Small Animal Practice, v. 44, n. 1, p. 95-105, 2014.

WHEELDON, E. B.; BREEZE, R. G.; PIRIE, H. M. Animal model: chronic bronchitis in dogs. American Journal of Pathology, v. 96, n. 1, p. 355-358, 1979.
YBARRA, W. L.; JOHNSON, L. R.; DRAZENOVICH, T. L.; JOHNSON, E. G.; VERNAU, W. Interpretation of multisegment bronchoalveolar lavage in cats $(1 / 2001-$ 1/2011). Journal of Veterinary Internal Medicine, v. 26, n. 6, p. 1281-1287, 2012.

ZHU, B. Y.; JOHNSON, L. R.; VERNAU, W. Tracheobronchial brush cytology and bronchoalveolar lavage in dogs and cats with chronic cough: 45 cases (2012-2014). Journal of Veterinary Internal Medicine, v. 29, n. 2, p. 526-532, 2015. 
